\title{
QUAIS CONTEÚDOS EMERGEM DAS INSTÂNCIAS ESPECÍFICAS RECEBIDAS PELO PCN BRASIL? REFLEXÕES A PARTIR DE ANÁLISES LEXICAIS
}

Luíza Mônica Assis da Silva²

\begin{abstract}
SINOPSE
Os pontos de contato nacional (PCNs) são os responsáveis pelo encaminhamento das instâncias específicas, um mecanismo não judicial de denúncia de violação das Diretrizes para Empresas Multinacionais, instituídas pela Organização para a Cooperação e Desenvolvimento Econômico (OCDE), que contribui para a reparação dos danos causados pelas companhias por meio do acordo entre as partes. Apesar de várias pesquisas apontarem a relevância desse instrumento para a promoção da conduta empresarial responsável (CER) no ambiente de negócios internacional, ainda são poucos os estudos acadêmicos que investigam os conteúdos dos documentos das instâncias específicas. 0 objetivo desta pesquisa foi conhecer os conteúdos discursivos do sumário das instâncias específicas recebidas pelo PCN Brasil no período de 2003 a 2020. Para isso, foi realizada a análise documental com apoio do software Interface de $R$ pour les Analyses Multidimensionnelles de Textes et de Questionnaires (Iramuteq), que processa análises lexicais. Os resultados apontam que o PCN Brasil tem seguido as recomendações da OCDE na forma como lida com as instâncias. Além disso, apesar de recente, o Manual de Procedimentos tem colaborado para uma maior transparência dos processos. Os achados também sugerem pouca interlocução com diferentes organizações da sociedade civil e que a fase dos bons ofícios (mediação) precisa ser fortalecida.
\end{abstract}

Palavras-chave: ponto de contato nacional; PCN Brasil; OCDE; conduta empresarial responsável; instâncias específicas.

\begin{abstract}
The National Contact Points (NCPs) are responsible for managing the specific instances, a non-judicial mechanism for denouncing violations of the Guidelines for Multinational Enterprises, established by the Organization for Economic Cooperation and Development (OECD), that contributes to repairing the damages caused by companies by means of agreement between the parties. Although several studies have pointed out the relevance of this instrument for the promotion of Responsible Business Conduct (CER) in the international business environment, there are still few academic studies that investigate the content of the specific instances' documents. The aim of this article is to apprehend the discursive content of the summaries of the specific instances received by NCP Brazil from 2003 to 2020. A documentary analysis is carried out using Iramuteq (Interface de R pour les Analyzes Multidimensionnelles de Textes et Questionnaires), a software that process lexical analyses. The results show that, regarding the way it deals with the specific instances, NCP Brazil has been following the OECD's recommendations. Furthermore, despite its recent introduction, the Manual of Procedures has contributed to greater transparency of processes. The findings also suggest little dialogue with different organizations of the civil society and that the phase of good offices (mediation) needs to be strengthened.
\end{abstract}

Keywords: national contact point; NCP Brazil; OECD; responsible business conduct; specific instances.

JEL: F53; M14.

Artigo recebido em 26/4/2021 e aprovado em 30/4/2021.

DOl: http://dx.doi.org/10.38116/bepi29art5

1. Este artigo foi financiado com recursos da Comissão Econômica para a América Latina e o Caribe (Cepal).

2. Doutora em psicologia social do trabalho e das organizações pela Universidade de Brasília (UnB) e mestre em Ciência Política pela UnB; docente e pesquisadora nas áreas de processos comunicacionais nas organizações e responsabilidade social das empresas; e consultora de comunicação organizacional. 


\section{INTRODUÇÃO}

As Diretrizes para Empresas Multinacionais ${ }^{3}$ fazem parte do documento Investimento Internacional e Empresas Multinacionais, elaborado pela Organizaçáo para a Cooperaçáo e Desenvolvimento Econômico (OCDE) e tratam da conduta empresarial responsável (CER). As Diretrizes funcionam, na prática, como mecanismo de soft law, e a adesão pelas empresas é voluntária. Entretanto, os países que aderem ao documento (incluindo membros e não membros da organização) assumem uma série de compromissos vinculativos e autorizativos relativos à promoção da CER.

Os temas ou capítulos do documento são abrangentes e tratam de: i) conceitos e princípios; ii) políticas gerais; iii) transparência; iv) direitos humanos; v) relaçôes laborais; vi) meio ambiente; vii) combate à corrupção, à solicitação de suborno e à extorsão; viii) interesses do consumidor; ix) concorrência; e x) tributação.

Desde a sua criação, em 1976, aconteceram cinco revisões das Diretrizes, em 1979, 1984, 1991, 2000 e 2011. As mudanças tiveram por objetivo esclarecimento e ampliação, com novos temas/capítulos, envolvendo questôes atinentes a meio ambiente, direitos humanos, direito do consumidor, combate à corrupção e compromisso da cadeia de fornecedores com a CER. As revisóes também inseriram procedimentos para a implementação das Diretrizes, para lidar com denúncias de violaçôes das Diretrizes (instâncias específicas) e para a elaboração de guias de due diligence, com o objetivo de tratar, mitigar e prevenir riscos de danos causados pelas empresas multinacionais (EMNs). Foram produzidos guias sobre diferentes setores econômicos, como vestuário e calçados, mineraçáo e financeiro, entre outros.

\section{OPERACIONALIZAÇÃO DAS DIRETRIZES}

\subsection{Os pontos de contato nacionais (PCNs)}

Todos os 49 países que aderiram às Diretrizes foram instados a criar a figura do PCN, destinando-lhe recursos humanos e financeiros necessários para o cumprimento de sua missão institucional, que é disseminar as Diretrizes junto às partes interessadas, operacionalizá-las e denunciar sua violação, propondo mecanismos extrajudiciais de mediação, bem como alternativas consensuais entre as partes e para a reparação de danos $(\mathrm{OECD}, 2020){ }^{4}$

Na revisão das Diretrizes ocorrida em 2000 definiu-se que os PCNs teriam em seu mandato um mecanismo não judicial para receber e mediar reclamações de violação das Diretrizes, denominado instância específica. ${ }^{5}$ Também foi criada pela OCDE uma base de dados aberta e informada pelos PCNs para publicizar as informaçôes sobre as denúncias recebidas, disponíveis na página da organização. ${ }^{6}$

\footnotetext{
3. Doravante denominadas Diretrizes.

4. A OCDE refere-se aos PCNs como "um mecanismo único de implementação da Responsabilidade Empresarial Corporativa com acesso a recursos em escala global e que fornece uma plataforma para mediação e conciliação" (OCDE, 2021, tradução nossa).

5. Neste texto utilizaremos os termos alegações de inobservância; reclamações; violações; instâncias específicas; denúncias; e alegações como sinônimos.

6. A base com informações de todos os PCNs está disponível em: <https://mneguidelines.oecd.org/database/>.
} 
A revisão das Diretrizes de 2011, implementada em 2012, promoveu, entre outras, mudanças nos procedimentos padronizados relativos às alegaçôes de violaçôes, visando garantir a uniformidade dos processos e condutas e maior transparência, visibilidade e previsibilidade de processos, independentemente do PCN em que as instâncias foram instauradas.

Os $48 \mathrm{PCNs}^{7}$ possuem diferentes arranjos institucionais, porém atuam de forma conjunta em redes de apoio e aprendizagem mútuas. O Secretariado da OCDE definiu uma série de requisitos para garantir a equivalência funcional entre os PCNs. Para assegurar o cumprimento de seu mandato em diferentes arranjos institucionais e estruturas, os seguintes critérios foram definidos: visibilidade, acessibilidade, transparência e accountability (figura 1). Ações e atividades são sugeridas de modo a cumprir esses critérios e são reportadas, anualmente, pelos PCNs ao Comitê de Investimentos e discutidas nos encontros entre os PCNs. Sáo também elementos de avaliação por pares (peer review) e de capacitaçóes promovidas pela OCDE.

\section{FIGURA 1}

\section{Critérios fundamentais para equivalência funcional}

\section{Core criteria for NCPS}
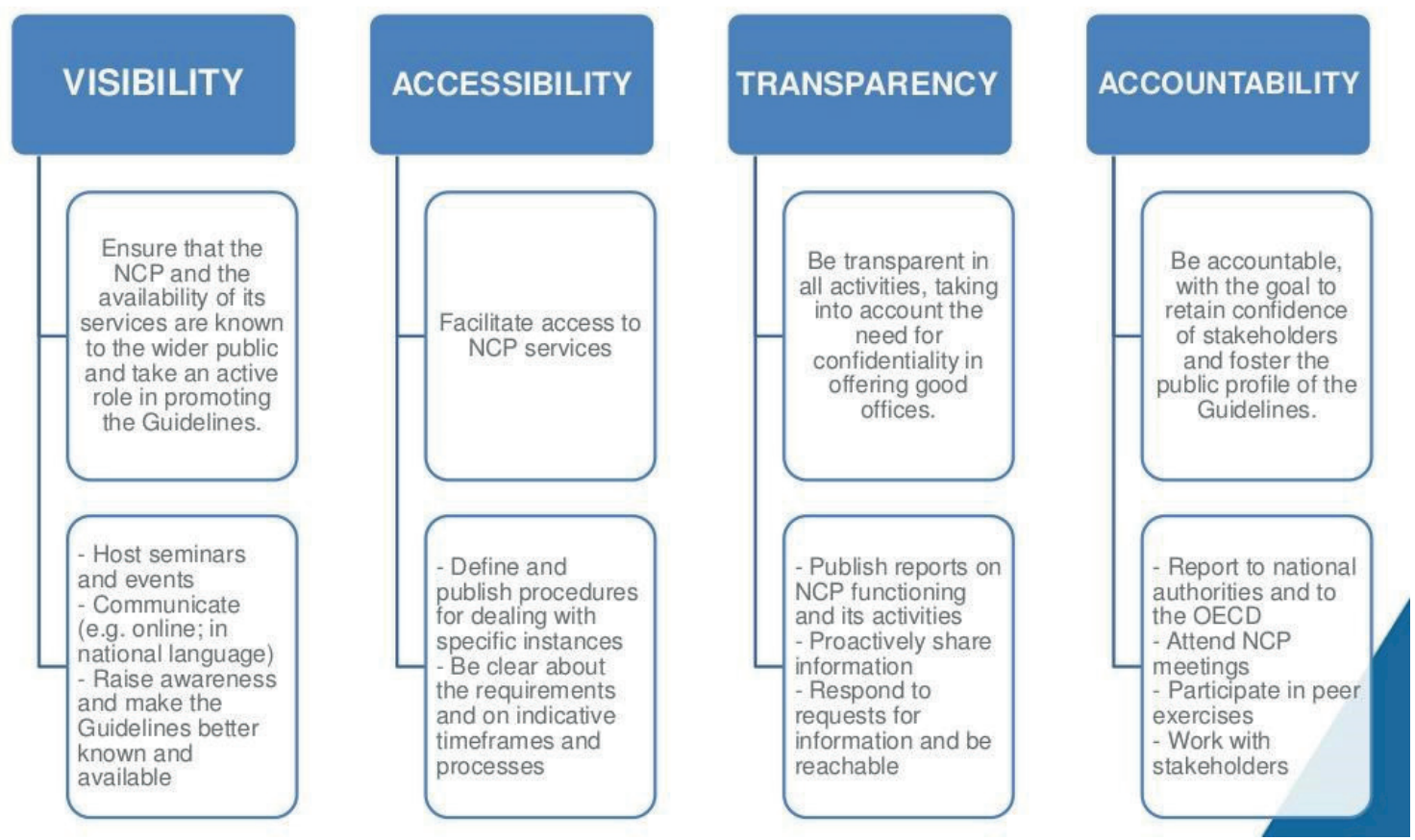

Fonte: OECD. Disponivel em: <https://www.slideshare.net/PamelaDuffin/ promoting-responsible-business-conduct-the-oecd-guidelines-for-multinational-enterprises-and-national-contact-points>. Acesso em: 27 mar. 2021.

Obs.: Figura cujos leiaute e textos não puderam ser padronizados e revisados em virtude das condições técnicas dos originais (nota do Editorial). 
O Brasil adotou uma estrutura interministerial de funcionamento para lidar com as instâncias específicas. ${ }^{8}$ Esse modelo tem a vantagem de dispor de uma variedade de especialistas entre os técnicos governamentais, sem necessidade de consulta externa, e pode ainda estimular a divulgação e a coerência com as Diretrizes entre variados órgãos do governo. Outro destacado benefício é estar menos sujeita a ser entendida como parcial ou tendenciosa por alguma das partes. Entre os desafios, está a ausência de conexóes com as partes interessadas, o que pode tornar mais difícil estabelecer relaçóes e conquistar confiança. Outro risco é o de que uma estrutura técnica, composta por vários órgáos e representantes, torne o processo de decisão mais lento e o consenso mais difícil (OECD, 2019).

\subsection{Instâncias específicas}

Uma das principais funçôes dos PCNs é receber e lidar com denúncias encaminhadas por indivíduos e/ou uma variedade de tipos de organizaçóes (empresariais, representativas de empresas, sindicatos de trabalhadores, organizaçóes não governamentais etc.), que são denominados alegantes, em contraposição às multinacionais denunciadas, as alegadas.

Os PCNs devem seguir procedimentos gerais recomendados pelo comitê, assim como aprovar um manual de procedimentos para instâncias específicas domésticas, preferencialmente elaborado e discutido por meio de consulta pública, permitindo, dessa forma, que seu mandato seja exercido. O documento deve apresentar a forma de lidar com as alegaçóes e deve estar de acordo com a estrutura e os recursos técnicos e financeiros disponíveis. O manual deve ser disponibilizado no idioma nacional e, preferencialmente, também em inglês e de modo on-line no site da agência.

A OCDE definiu três fases para as instâncias específicas a serem adotadas pelos PCNs, ainda que estes possam adaptá-las à sua realidade. São elas: avaliação inicial, bons ofícios e conclusão. A figura 2 descreve, sucintamente essas três fases.

Na primeira fase, chamada avaliaçáo inicial (initial assessment), o processo é analisado pelos requisitos e informaçóes iniciais do alegante (quem submete à instância específica) e da alegada (empresa denunciada). Adota-se um formulário padrão encaminhado a um relator que decide, com base nos princípios das Diretrizes, por sua aceitação ou rejeição. Quando não aceita, a alegação é automaticamente encerrada, e uma declaração deve ser publicada na página do PCN. Essa etapa tem duração prevista de três meses. O nome da empresa alegada é resguardado pela confidencialidade até a aceitação da instância específica.

A segunda fase, denominada bons ofícios (good offices), é a mais importante, pois busca a conciliação, o consenso e a reparação entre as partes e conta com um mediador. Recomenda-se que o prazo de duração dessa etapa seja de seis meses. A OCDE criou um guia sobre mediação e capacitaçóes específicas para essa fase, dada a complexidade da etapa.

A terceira fase, nomeada conclusão (conclusion), acontece quando: não há aceitação da denúncia; uma das partes decide não participar do processo; não é possível um acordo entre as partes; ou um

8. Outros arranjos institucionais possíveis são: i) Agência Única - o órgão é composto por um único indivíduo ou ministério ou um grupo de indivíduos de um mesmo ministério; ii) Agência Multipartite - o PCN é composto por um grupo de oficiais de governo e representantes das partes interessadas como governos, empresas, sindicatos e organizações da sociedade civil; iii) Grupo de Especialistas - no qual os membros são indicados pelo governo, mas são externos a este, sendo, portanto, estruturas independentes e não-governamentais que recebem recursos oficiais; e iv) Estruturas Híbridas - podem ser agências únicas ou múltiplas, compostas por especialistas (OECD, 2020). 
acordo é alcançado. Em caso de não aceitação, o PCN faz uma declaração e algumas recomendaçóes. Nas situaçôes em que as partes não entram em acordo ou quando este é celebrado, o PCN prepara o final statement com recomendaçóes e publica o resultado. A previsão de duração dessa fase é de três meses.

\section{FIGURA 2}

\section{Fases das instâncias específicas}

\section{Specific instances - process}

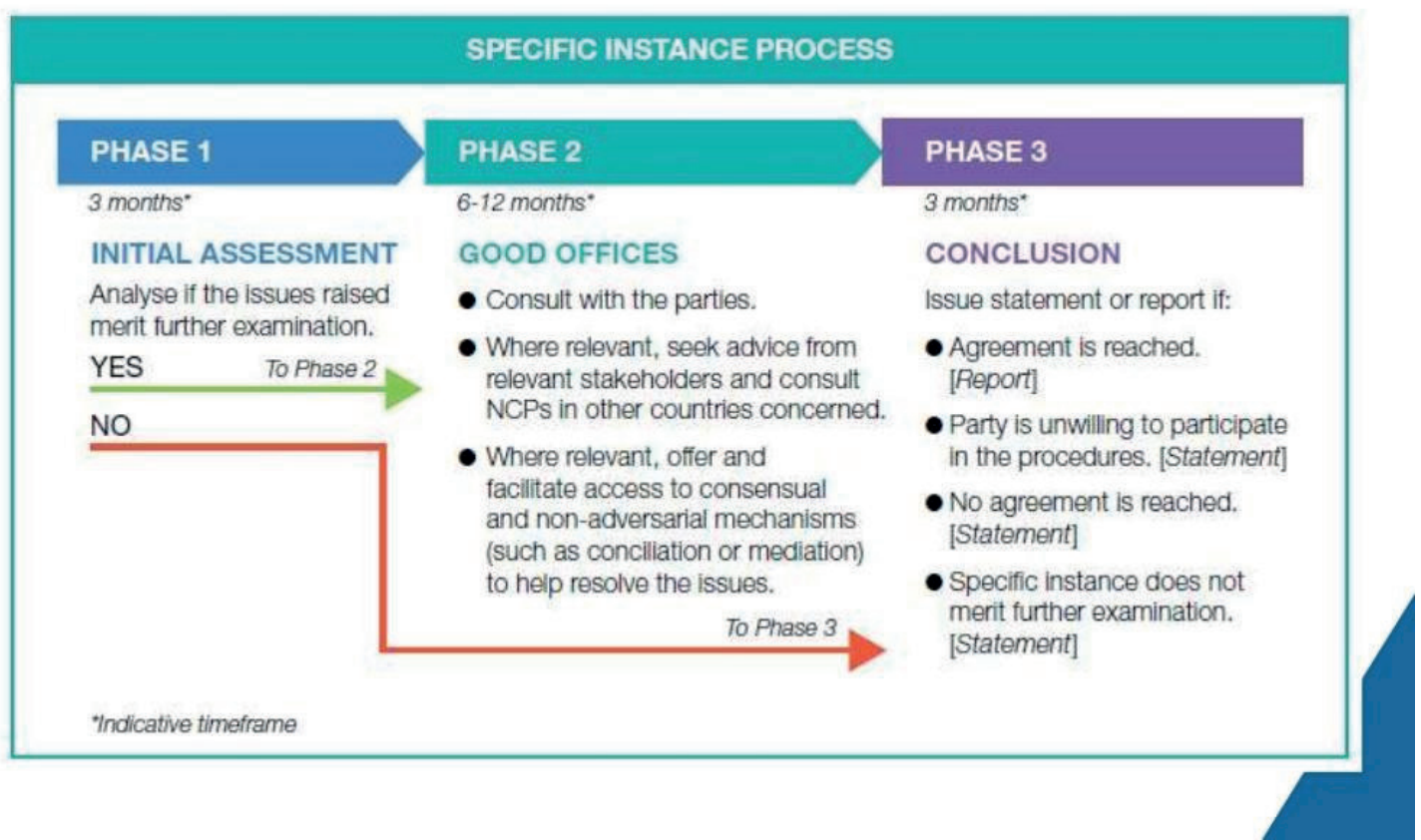

Fonte: OECD. Disponível em:<https://www.slideshare.net/PamelaDuffin/ promoting-responsible-business-conduct-the-oecd-guidelines-for-multinational-enterprises-and-national-contact-points>. Acesso em: 27 mar. 2021.

Obs.: Figura cujos leiaute e textos não puderam ser padronizados e revisados em virtude das condições técnicas dos originais (nota do Editorial).

O prazo recomendado para resolução é de doze meses, mas na maior parte das vezes acontecem atrasos por diferentes motivos - por exemplo, quando vários países estáo envolvidos, quando a denúncia se origina de um país que não aderiu às Diretrizes ou quando o processo de mediação é mais complexo (OECD, 2012).

Todas as fases contam com o apoio da OCDE na resolução de dúvidas e esclarecimentos das Diretrizes. Além disso, o Secretariado oferece capacitações para as equipes técnicas dos PCNs. As instâncias específicas podem envolver mais de um PCN. Em casos de denúncia de comportamento de uma empresa atuando em outro país, o PCN do país de origem do capital também participa do processo. Em casos mais complexos, dependendo da questáo e do porte da transnacional, podem ser envolvidos múltiplos PCNs e a coordenação da OCDE. 
Uma fase adicional, não obrigatória, é a de acompanhamento (follow up). O PCN busca supervisionar a implementação do acordo entre as partes e/ou as recomendaçôes que fizeram às empresas após a conclusão dos casos. Trata-se de uma etapa sem previsão de prazo, que fica a critério dos países.

Diante do exposto, podemos perceber que a OCDE, em conjunto com os PCNs, definiu uma série de regras e recomendaçóes para o tratamento das instâncias específicas e promoção de sua eficácia. Entretanto, existem críticas e ressalvas sobre a eficácia do mecanismo de reclamaçóes. A primeira delas refere-se a sua natureza voluntária e à ausência de sançôes. Para a organização não governamental (ONG) OECD Watch, ${ }^{9}$ as principais falhas do mecanismo se referem a sua relação com a sociedade civil e como instrumento de pressão para adoção da CER. Apenas 25\% dos PCNs emitem declaraçôes de que as empresas violaram as Diretrizes, o que impede a auditagem de possíveis investidores.

Apenas $10 \%$ atribuem consequências quando as empresas se recusam a participar de bons ofícios. Apenas um terço dos PCNs acompanha consistentemente as reclamaçóes concluídas para verificar se as empresas realmente implementaram os acordos e recomendaçóes. A mesma proporçáo dos PCNs não publicou regras de tratamento de reclamaçóes em inglês e em seu idioma nacional e alguns sequer têm regras de procedimento (OECD Watch, 2021).

Apenas um quarto dos PCNs atende às expectativas das organizações da sociedade civil (OSCs) quanto à transparência no processo de reclamação. Para a OECD Watch esses fatores são fundamentais para estabelecer expectativas claras sobre as empresas e vital para investidores que buscam aplicar recursos em empresas responsáveis (OECD Watch, 2021).

Também em relação à ausência de mecanismos de controle e pressão sobre as empresas, apenas $12 \%$ dos governos atribuem consequências às empresas que se recusam a se envolver de boa-fé no processo do PCN. No que diz respeito às comunicaçóes das alegaçóes, menos da metade dos PCNs têm um banco de dados com informaçóes. $\mathrm{O}$ acompanhamento acontece em apenas $33 \%$ dos casos para verificar se recomendaçôes e acordos foram cumpridos. Apenas $25 \%$ conseguem atender às expectativas de transparência da sociedade civil em relação ao processo de queixa. Apenas $50 \%$ dos PCNs publicam todas as declaraçóes em sua página web, apesar de esta ser uma regra vinculativa, e um pequeno grupo de $25 \%$ publica as avaliaçôes iniciais das denúncias (OECD Watch, 2021).

Esses dados revelam o desafio dos PCNs no cumprimento de seu mandato. Lembramos que mecanismos com características de autorregulação, ausência de sançóes e adesão voluntária podem ser ineficazes, principalmente em épocas de acirrada crise e desigualdade econômica e de poder entre os stakeholders, uma vez que a natureza das empresas está voltada para a busca do lucro, e sua participação é voluntária. Já autores como Backer (2009) destacam que, mesmo a "pequenos passos", o mecanismo das alegaçóes pode servir de ponto inicial para a mudança de comportamento das empresas e para a mudança na legislação interna dos países sobre a CER.

9. A OECD Watch é uma rede de organizações da sociedade civil que está presente em mais de cinquenta países. Composta por mais de 130 organizações, a instituição faz parte do Conselho Consultivo da OCDE, juntamente com a Trade Union Advisory Committee (TUAC) e a Business at OECD (BIAC). É interlocutora da sociedade civil para defender os interesses das ONGs na responsabilização e reparação de danos por parte das empresas. Busca defender os interesses de indivíduos nas relações de má conduta das empresas e realiza sua missão por meio do monitoramento dos mecanismos de implementação das Diretrizes e dos PCNs. 


\subsection{Como o PCN Brasil lida com as instâncias específicas}

O PCN Brasil foi criado por meio da Portaria no 92 do Ministério da Fazenda, de 12 de maio de 2003, permanecendo subordinado a esse ministério por quase dezesseis anos. Em 2016 passou a ter um funcionário com dedicação exclusiva (coordenador); e a partir de 2017, a contar regularmente com funcionários em tempo parcial, mas com mudanças frequentes no grupo. Desde 2020 conta com uma coordenação técnica composta por três servidores sêniores com elevada qualificação. Essa equipe é responsável por verificar se a alegação encaminhada por meio de formulário cumpre os requisitos de admissibilidade. Em caso positivo, o coordenador do PCN, após consultar o Grupo de Trabalho Interministerial (GTI), encaminha a instância para o relator mais adequado do colegiado interministerial.

Em 27 de junho de 2019, o governo brasileiro publicou o Decreto no 9.874, que instituiu o PCN Brasil e detalhou suas funçôes e atividades; número de representantes; composição interministerial; ${ }^{10}$ número de reuniôes e quórum de participação; membros titulares; funçôes do coordenador; além de listar outros órgáos competentes para seu assessoramento nas áreas de tributação, advocacia da União e meio ambiente. O PCN fica sediado no Ministério da Economia, sendo supervisionado pelo Comitê de Investimentos. Alguns meses depois, foi editada a Portaria Interministerial no 548 , que designa nominalmente os membros titulares e suplentes. Neste ano, foi aberto o processo de consulta pública para elaboração do Manual de Procedimentos para Instâncias Específicas, ${ }^{11}$ do qual participaram várias partes interessadas.

O Manual de Procedimentos, aprovado em 2020, é um documento extremamente importante, uma vez que apresenta com clareza as regras para lidar com as instâncias específicas e objetiva dar previsibilidade e transparência ao processo. Esclarece os requisitos necessários para apresentação das alegaçóes e explicita todas as etapas do processo. O documento está on-line na página do PCN Brasil e tem como anexo o formulário de submissão das instâncias que podem ser enviadas por e-mail (Brasil, 2020). Com a adoçáo do manual pode-se inferir que o processo de submissóes ficou mais claro, acessível, previsível e mais didático, o que pode levar ao aumento do número de submissóes. Após a publicação, o PCN Brasil recebeu seis novas denúncias no ano de 2020, das quais cinco foram aceitas e estão em curso. ${ }^{12}$

O órgão brasileiro busca cumprir as etapas definidas pela OCDE - avaliação inicial, bons ofícios e conclusão -, com algumas adaptaçóes e modificaçóes, mas buscando manter a equivalência funcional. Desse modo, cumpre a maioria dos requisitos vinculativos e autorizativos da agência, como ter um banco de dados com as alegaçóes de inobservância. ${ }^{13}$

10. A composição, colegiada, é a seguinte: três representantes do Ministério da Economia, sendo um representante da Secretaria Especial de Comércio Exterior e Assuntos Internacionais (coordenador), um representante da Secretaria Especial de Previdência e Trabalho e um representante da Secretaria Especial de Produtividade, Emprego e Competitividade. Os ministérios da Justiça e Segurança Pública, Relações Exteriores, Minas e Energia, Meio Ambiente, Controladoria Geral da União, da Mulher, Família e Direitos Humanos e o Banco Central do Brasil também possuem representantes.

11. Antes do manual havia a Resolução no 1/2012, com procedimentos para lidar com instâncias específicas, de acordo com o guia de procedimentos da OCDE.

12. Consulta realizada em abril de 2021.

13. 0 endereço do banco de informações é: <https://www.gov.br/produtividade-e-comercio-exterior/pt-br/assuntos/camex/pcn/produtos/ alegacoes-de-inobservancia/instancias-especificas-alegacoes-de-inobservancia-das-diretrizes-da-ocde>. 
Conforme o banco de dados disponibilizado no site, que apresenta o status das alegaçóes, o PCN Brasil tem conseguido lidar razoavelmente bem com a conclusão dos casos que recebeu de 2003 a 2020: 56\% foram concluídos; 25\% não foram aceitos; e 19\% estão em progresso (gráfico 1). Chama a atenção o percentual de $25 \%$ de não aceitas, mas que está abaixo do percentual para o conjunto dos PCNs no período 2000-2018, estimado em 36 \%, e do ano de 2019, que ficou em 60\%.

\section{GRÁFICO 1}

Status das alegações ao PCN Brasil (2003-2020)

(Em \%)

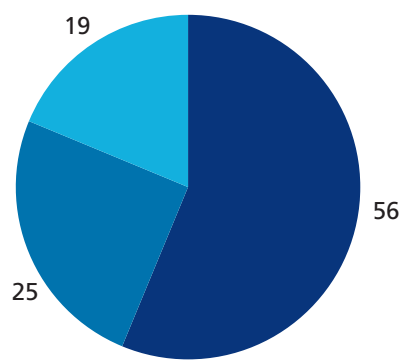

Concluído $\quad$ Não aceito Em progresso

Fonte: Banco de dados da OCDE sobre instâncias específicas. Disponivel em: <https://mneguidelines.oecd.org/database/>. Acesso em: 27 mar. 2021. Elaboração da autora.

O número de instâncias recebidas e o prazo de resolução não devem ser, todavia, os únicos parâmetros de efetividade dos PCNs. Como exemplo do primeiro caso, temos o PCN Japão, que apesar de ser bem avaliado pelos pares e de sólidas açôes de CER de suas multinacionais, têm relativamente poucas denúncias (OECD, 2012).

Os prazos, muitas vezes, espelham a complexidade das denúncias e a dificuldade em fechar acordo. Um dos casos concluídos em 2019 levou oito anos para ser finalizado (OECD, 2020). Por seu turno, PCNs que resolvem rapidamente as instâncias específicas podem ter interpretado de forma equivocada ou bastante restrita os capítulos das Diretrizes, o que implica em um alto grau de rejeição das denúncias e, consequentemente, rápida resolução. Poucas denúncias e rápida resolução também podem sugerir que o instrumento de alegaçóes de inobservância é pouco conhecido pelas partes interessadas e/ou que não tem a confiança dos alegantes.

As instâncias específicas têm sido pouco exploradas pela pesquisa acadêmica, apesar da diversidade de estudos técnicos produzidos pela OCDE. Na revisão de literatura empreendida para este trabalho nas bases científicas que compôe o Portal da Coordenação de Aperfeiçoamento de Pessoal de Nível Superior (CAPES) foram encontrados apenas três resultados para os termos national contact point specific instance. Um dos trabalhos refere-se, especificamente, à análise de estudos de caso, e os outros dois versam sobre corporaçôes e direito internacional. Os artigos sobre os PCNs são abundantes e ultrapassam 16 mil textos, nos últimos cinco anos, mas não abordam especificamente as alegaçóes. A busca para national contact point specific instance Brazil não obteve resultado, sendo, portanto, um indicativo de que o tema ainda náo foi devidamente abordado pelas publicaçóes científicas disponíveis no portal. 
O exame das instâncias específicas recebidas pelo PCN Brasil é central neste trabalho, dada a sua relevância no mandato dos PCNs para promoção e implementação das Diretrizes. Desse modo, com base nas recomendaçóes da OCDE e do guia de procedimentos, recentemente elaborado e publicado pelo PCN Brasil (em fevereiro de 2020), a análise das alegaçóes nos permitiria, em princípio, observar quais procedimentos são aplicados, de que forma e com quais resultados. De acordo com o exposto, e diante da carência de pesquisas sobre esse objeto, examinaremos, por meio de análises lexicais, os documentos relativos às instâncias específicas recebidas pelo PCN Brasil, com o objetivo de conhecer o conteúdo das alegaçóes de inobservância encaminhadas no período de 2003 a 2020.

\section{METODOLOGIA: ANÁLISES LEXICAIS DAS INSTÂNCIAS ESPECÍFICAS}

A OCDE estabelece que os PCNs disponibilizem no site todas as alegaçôes de inobservância recebidas, independentemente de seus status (aceita, não aceita ou concluída), bem como os textos das declaraçóes e declaraçôes finais. O PCN Brasil, por problemas em seu sistema de informação, não apresenta as declaraçôes finais, ${ }^{14}$ apenas parte das informaçóes relativas às instâncias, a saber:

- número da alegação de inobservância;

- data;

- alegado e alegante - em caso de não aceitação da alegação, o nome da empresa é mantido em confidencialidade;

- status;

- PCN responsável e de apoio, quando houver;

- descrição: identificação do alegante e do alegado (somente em caso de aceitação);

- $\quad$ tema(s) das Diretrizes violados;

- $\quad$ país de ocorrência;

- $\quad$ parte interessada;

- $\quad$ setor da alegação; e

- $\quad$ sumário contendo uma breve descrição da denúncia, envolvidos e a fase de andamento em que se encontra.

O site informa que

as Declaraçôes do PCN são públicas, com exceção das informaçōes para as quais uma das partes solicitar expressamente confidencialidade. Tais documentos são encaminhados às partes, à OCDE e aos PCNs dos países sedes das empresas multinacionais partes no processo e divulgados na página do PCN. ${ }^{15}$

14. Trata-se de documentos que devem ser públicos e conter uma visão geral do caso e a descrição do processo. Em caso de rejeição, descreve como a instância foi avaliada, sem apreciação de mérito. Em caso de aceitação sem acordo nos bons ofícios ou desistência de participação, enumera as questões levantadas, a assistência ofertada pelo PCN às partes, as posições das partes e possíveis razões pelas quais as empresas não chegaram a um acordo. Em caso de acordo, lista todos os procedimentos da mediação e assistência oferecida, compromissos acordados pelas partes e recomendações. O PCN Brasil escolheu em seu manual de procedimento não distinguir os documentos de conclusão entre declaração e declaração final, e sim usar apenas declaração final que deve ser aprovada pelo GTI-PCN.

15. Disponivel em: <https://bityli.com/DloQh>. Acesso em: 5 jan. 2021. 
Como não tínhamos acesso aos documentos relativos às declaraçóes finais, ${ }^{16}$ mais completos, optamos por analisar os resumos disponíveis por meio de análises lexicais informatizadas. Esse tipo de exame, mais objetivo, ${ }^{17}$ permite uma série de análises sobre a especificidade dos discursos do PCN Brasil, sintetiza com sucesso os principais conteúdos e a forma de trabalho do PCN.

Nas análises realizadas optamos por utilizar o Interface de R pour les Analyses Multidimensionnelles de Textes et de Questionnaires (Iramuteq), um software francês, gratuito, desenvolvido por Pierre Ratinaud, em 2009, que utiliza o ambiente estatístico do software R (Salviati, 2017). Entre outras funçôes, possibilita análises textuais pelo Método Reinert, um tipo de análise automática de discurso, desenvolvida por Max Reinert, em 1979.

O programa possibilita realizar análises lexicais em diferentes idiomas e desde 2013 tem sido utilizado em variadas pesquisas no Brasil. No caso das pesquisas documentais, pode ser utilizado com vantagens em relação à tradicional análise manual de conteúdo categorial temática, descrita por Bardin (2007). É uma ferramenta extremamente útil na análise de textos resultantes de entrevistas, grupos focais, redes sociais, questôes abertas de questionários, resumos em bases de dados, entre outros.

Basicamente, o programa sintetiza as informaçóes textuais e classifica as mais importantes, por meio de estatísticas como o $\chi^{2}$ (qui-quadrado) e análises fatoriais do corpus textual, ${ }^{18}$ realiza a classificação dos enunciados simples do texto em função da distribuição das palavras, identificando os vocábulos mais característicos. Além disso, o software permite acessar as representaçóes presentes em mensagens textuais, sem que haja perda de sua dinâmica e complexidade (Oliveira, Gomes e Marques, 2005). Por meio dos vocábulos mais característicos e da apresentação gráfica das análises fatoriais, é possível identificar diferentes lugares de fala, contradiçóes, bem como os temas característicos de um determinado gênero do discurso (Lima, 2008). A seguir, a título de exemplificação, apresentamos, resumidamente, a descrição dos processamentos do software na análise Reinert padrão que utilizamos.

O pesquisador prepara o corpus formatando o texto com a retirada de siglas, aspas, asteriscos, hifens, símbolos matemáticos e padroniza os vocábulos que devem ser analisados conjuntamente. Define os textos por meio de variáveis, por exemplo: fase da instância específica, alegante, alegada, relator etc. e as registra antecedidas por linhas com asterisco. Após o processamento, primeiramente, o programa divide o texto em unidades com três linhas em média, contendo até 250 caracteres para criação dos segmentos de texto. Esses segmentos são definidos com base na ordem em que aparecem no texto e na pontuação. Para isso, o texto é todo "picotado" em frases. Depois, é feita a contagem do radical de todas as palavras, o que possibilita o cálculo de coocorrências de palavras que pertencem ao mesmo grupo lexical. Após esses procedimentos é criado o dicionário de formas reduzidas.

As informações obtidas nessa análise inicial são apresentadas num relatório e referem-se: ao número de segmentos de texto que foram indexados pelo pesquisador; número total de palavras; número de vocábulos distintos; média de aparecimento de uma palavra; número de palavras que aparecem

\footnotetext{
16. No período de coleta de dados desta pesquisa (dezembro de 2020 a março de 2021) o link de acesso das declarações finais não disponibilizava os arquivos das declarações finais. Em abril de 2021, a página do PCN passou a disponibilizar as declarações finais mais recentes, mas não de todas as alegações submetidas ao órgão.

17. Em análises de conteúdo tradicionais, método manual, recomenda-se que as interpretações do pesquisador sobre os conteúdos de um texto passem pela supervisão de juízes que avaliam as categorias criadas em relação a: pertinência ou validade, exaustividade ou inclusividade, homogeneidade e, finalmente, consistência/fidedignidade.

18. É o conjunto dos textos construídos pelo pesquisador e que forma o objeto de interpretação. Em nosso caso, o corpus é formado pelo conjunto das alegações de inobservância das Diretrizes.
} 
apenas uma vez, denominadas hápax; número de formas antes da redução ao radical; número de ocorrências que definem os segmentos de textos; número de variáveis; porcentagem de riqueza do vocabulário; frequência mínima de palavras; número médio de palavras analisadas por segmento de texto; número de formas (palavras).

Numa segunda fase, é realizada a classificação descendente hierárquica $(\mathrm{CDH})$. Ainda nessa etapa, é obtido um dendrograma, com a divisão dos segmentos do texto em classes, nas quais existe uma grande homogeneidade de temas tratados e que apresenta o índice de relaçáo entre as classes, similaridade ou distância. É possível, nesse momento, identificar os principais eixos temáticos de um discurso.

Numa terceira fase, também resultante da $\mathrm{CDH}$, são apresentadas as análises fatoriais de correspondência sob a forma de gráficos que nos permitem localizar espacialmente as classes, sua proximidade, intersecçôes, distanciamento e oposição.

A quarta fase permite a interpretação dos dados por meio de um detalhamento das classes encontradas - seleção dos segmentos de texto mais representativos; listas das palavras com maiores $\chi^{2}$; palavras de presença significativa; palavras com ausência significativa; variáveis mais significativas por classe.

O Iramuteq nos permite fazer uma grande síntese do discurso, seus principais eixos, temas de cada classe exemplificadas com os trechos textuais mais significativos. Esses pequenos fragmentos textuais são representativos do discurso específico daquela classe e não de um segmento de texto, por exemplo, de uma única alegação, mas sim de um conjunto de alegaçóes que fazem parte de uma mesma categoria temática. É fundamental que seja descrito/transcrito de modo a dar maior clareza e objetividade à interpretaçáo realizada pelo pesquisador.

O material do corpus foi extraído do site do PCN Brasil, no botão Consultar as alegaçóes de inobservância já recebidas pelo PCN. Os documentos relativos à declaraçáo final e ao relatório das açóes em andamento náo estavam disponíveis nos respectivos links (período de dezembro de 2020 a 14 de março de 2020). Desse modo, optou-se por utilizar o "sumário" das alegaçóes da página, que contém informaçóes sobre a data de início, alegantes e alegadas e descrição da denúncia, possível conclusáo e/ou etapa de andamento.

A lista de alegaçóes contempla um total de quarenta instâncias relativas ao período 2003-2020, mas desse conjunto constavam os sumários de 38 documentos. ${ }^{19}$ As alegaçóes disponíveis foram integralmente lidas, copiadas do site e formatadas de acordo com os padrôes para análise do software.

Foram definidas as seguintes variáveis de análise para os segmentos de texto, de acordo com o status definido pelo PCN Brasil: i) concluída (*concluída), com total de 21 sumários; ii) aceita em curso (*aceitaemcurso), com total de dez sumários; e iii) não aceita (*naoaceita), num total de sete sumários.

19. Note que esses dados divergem do banco de dados da OCDE, que apresenta 33 alegações recebidas. Nesse período, o site do PCN Brasil apresenta 36 alegações (de 2018 a 2019 não houve recebimento) e recebeu mais seis em 2020. A página da OCDE que permite a pesquisa por cada PCN individualmente, mas como já advertimos, pode não estar atualizada, apresenta 32 instâncias. 


\section{RESULTADOS E DISCUSSÃO DAS ANÁLISES LEXICAIS}

Foram indexadas 38 alegaçóes que geraram, consequentemente, um corpus textual com 38 textos. Após o processamento, como resultado, obtivemos 283 segmentos de texto e 9.843 ocorrências. Destas, um total de 594 (6\%) aparecem uma única vez (hápax), o que mostra que o vocabulário náo é diversificado, mas refere-se a um discurso específico sobre os procedimentos e violaçóes sobre as Diretrizes e, possivelmente, relativos às violaçóes mais denunciadas. Foram identificadas 1.587 formas ou palavras.

\subsection{Classificação hierárquica descendente}

A figura 3 apresenta a classificaçáo hierárquica descendente. Tomando-se a parte de cima do dendrograma, podemos inferir que os textos sobre as alegaçóes de inobservância dividem-se em dois eixos principais, com base no cálculo de proximidade entre as classes, que mostra que elas tratam de temas relacionados. O primeiro eixo, composto pelas classes 1 e 2, denominamos Procedimentos do PCN Brasil. O segundo foi intitulado Diretrizes da OCDE para empresas multinacionais - quem denuncia e o que denuncia e é composto pelas classes 3, 4 e 5 .

\section{FIGURA 3}

Classificação hierárquica descendente das alegações: palavras mais representativas das classes (2003-2020)

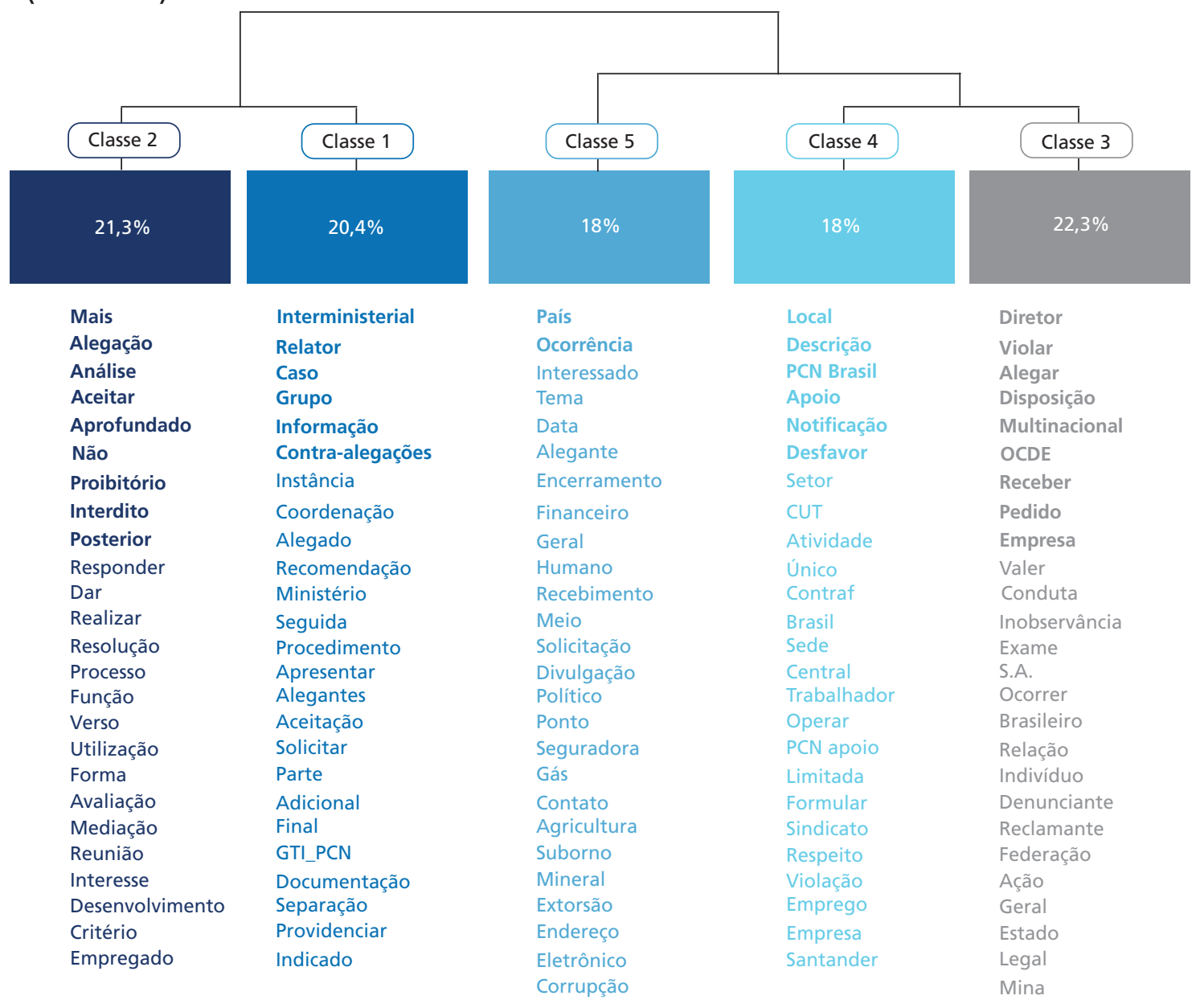




\subsubsection{Eixo 1: procedimentos do PCN Brasil}

A classe 2 é composta por 21,3\% do corpus. Entre as palavras mais representativas estão: mais, alegação, análise, aceitar, aprofundado, não, interdito, posterior, responder e realizar. A classe versa, principalmente, sobre os motivos para não continuidade e trata dos motivos de rejeição da denúncia prazo ultrapassado segundo as normas; análise mais aprofundada sobre a alegação; o alegante desistiu da ação; resolução judicial; encerramento judicial da empresa; e resolução direta entre as partes. A variável mais característica da classe é *nãoaceita. A seguir, a reconstituição do discurso da classe composto por algumas palavras e segmentos de maior $\chi^{2}$ que mostram que se refere às alegaçóes não aceitas. Cabe ressaltar que se trata de um resultado gerado pelo software, não refletindo uma alegaçáo específica ou trechos desta, podendo até incluir sentenças conflitantes em uma mesma classe.

A data de ocorrência deste evento não permite a aceitação da notificação, uma análise aprofundada ao não estar em acordo com a resolução que regulamenta o PCN Brasil. O PCN decidiu não aceitar esta notificação, após uma análise mais aprofundada. O PCN contatou a ONG, solicitando mais informaçôes, mas a $\mathrm{ONG}$ não as encaminhou. $\mathrm{O}$ alegante não manifestou interesse de que o caso tramitasse no Brasil. Durante a análise o relator verificou que houve transcurso de prazo superior a doze meses entre o conhecimento das demissōes e o recebimento da alegação.

A classe 1 compóe $20,4 \%$ do corpus e tem as seguintes palavras com maior $\chi^{2}$ : interministerial; relator; caso; grupo; informação; contra-alegações; instâncias; coordenação; alegaçôes; recomendação; ministério; seguida; procedimento; apresentar; alegantes; aceitação; solicitar, parte; adicional; grupo de trabalho; documentação; e providenciar. É formada por palavras características da variável *aceitaemcurso. Trata, principalmente, da fase de avaliação inicial, após a verificação do cumprimento dos requisitos de admissibilidade. Por se tratar de uma estrutura interministerial, essa palavra aparece em primeiro lugar. A definição da coordenação, a escolha do relator em função do ministério, os procedimentos seguidos para mais informaçôes dos alegantes e contra-alegaçóes e os documentos adicionais das partes alegantes e alegadas também aparecem no ranking. A seguir, um trecho representativo do discurso da classe.

A coordenação do PCN Brasil informou às partes alegantes que o grupo interministerial entendeu pela admissibilidade e aceitação do caso. As alegaçôes foram recebidas e encontram-se sob análise. Em seguida foi indicado o relator do ministério no âmbito do GTI, representante titular de Minas e Energia. Tendo em vista que a declaração final estipulou algumas recomendaçóes à empresa alegada, a coordenação do PCN estabeleceu o prazo de $1{ }^{\circ}$ de março para que sejam apresentadas informaçóes sobre a implementação de tais recomendaçôes. Após exame da documentação, o GTI decidiu por solicitar informaçôes adicionais conforme despacho do relator. O GTI condicionou a continuidade do procedimento à separação por instância por empresa alegada, o que foi providenciado pelas partes alegantes. Em seguida, as partes foram notificadas e a alegada apresentou suas contra-alegaçóes. Na comunicação informou que os documentos já foram fornecidos ao alegante e que não aceita participar dos procedimentos no âmbito do PCN Brasil. As alegaçóes foram recebidas e encontram-se sob análise.

Esse eixo mostra claramente o rito processual do PCN Brasil, de acordo com o manual de procedimentos, que se institucionaliza a partir da chegada das alegaçóes, as diferentes etapas do processo de avaliação inicial e as regras de prosseguimento, bem como o cuidado nas análises processuais e para a não aceitação da denúncia. Pode-se verificar que as normas procedimentais têm sido seguidas, como também as orientaçôes da OCDE, de publicizar as açôes e consubstanciá-las. Percebe-se que, de fato, o GTI acompanha os processos por meio do relator e das decisóes colegiadas. 


\subsubsection{Eixo 2: Diretrizes da OCDE para empresas multinacionais: quem denuncia e o que denuncia}

No segundo eixo (classes 3, 4 e 5), as classes 3 e 4 estão mais próximas (ver figura 3). As palavras mais representativas da classe 3 são: diretrizes; violação; alegação; disposição; multinacional; OCDE; receber; pedido; empresa; Vale; inobservância. Aqui os destaques são as Diretrizes; os tipos de violação; e as empresas multinacionais, principalmente as estrangeiras, que violam as Diretrizes e, em menor escala, as multinacionais com sede no Brasil. O vocabulário pertence aos elementos discursivos da OCDE (vocabulário próprio da agência). Há também a referência ao trabalho em conjunto com outros PCNs, como pode ser visto no trecho a seguir.

Em maio de 2004, o PCN brasileiro recebeu um pedido de exame da ONG Movimento dos Atingidos por Barragens (MAB) alegando que a Usina Canabrava violou as disposiçóes de meio ambiente das Diretrizes no Brasil por meio da construção de uma barragem e de deslocamento das populaçóes locais. Esse PCN recebeu notificação de OSCs de que a Van Oord, empresa multinacional holandesa, tinha violado as disposições de políticas gerais de divulgação de direitos humanos e de meio ambiente das Diretrizes em Pernambuco, Brasil. De acordo com o reclamante, a supracitada empresa multinacional ao instalar-se em Gravataí criou um sindicato paralelo, o sindicato dos trabalhadores nas indústrias metalúrgicas mecânicas e de material elétrico de Gravataí. O PCN Alemão recebeu um pedido de exame de um indivíduo alemão alegando que uma empresa multinacional tinha violado as disposiçóes de políticas gerais e de direitos humanos das diretrizes em Bangladesh (tema: políticas gerais e direitos humanos; país da ocorrência Bangladesh: alegante: manifestação individual; setor: manufatura).

A classe 4 tem por principais vocábulos: local; descrição; PCN Brasil; apoio; notificação; desfavor, CUT (Central Única dos Trabalhadores), CONTRAF (Confederação Nacional dos Trabalhadores do Ramo Financeiro). Essa classe, muito próxima em conteúdo da anterior, refere-se mais claramente ao PCN Brasil e aponta notificaçóes em desfavor das empresas feitas pela CUT e sindicatos. Lembramos que parte significativa das alegaçóes recebidas pelo PCN Brasil refere-se a relaçóes de emprego e empresariais (17). A seguir, um trecho extraído da classe.

Nestlé grupo de ex-representantes Purina setor e local perda de emprego no setor manufatureiro no Brasil PCN Brasil. Descrição alegação notificada por grupo de ex-distribuidores relativa às atividades de empresa multinacional suíça no Brasil tema Políticas Gerais. Basf e CUT setor e local emprego e relaçōes do trabalho no Brasil, responsável PCN Brasil, descrição: alegação formulada pela CUT em representação dos sindicatos componentes da rede de trabalhadores na Basf América do Sul em desfavor da empresa Basf.

A classe 5, que representa 16\% do corpus, tem como palavras principais: país; ocorrência; interessado; tema; data; alegante; encerramento; financeiro; geral; direitos humanos; recebimento; solicitação; divulgação; políticas; agricultura; suborno. Fala sobre alegantes e alegados, do perfil dos alegantes (lembramos que são majoritariamente sindicatos, como indica a classe 4); e o tema de violação das Diretrizes em que a multinacional incorreu. $\mathrm{O}$ trecho a seguir apresenta as frases e palavras de maior $\chi^{2}$. Mais uma vez, lembramos que não se refere a uma alegação específica, foi montado a partir do relatório do software, com as palavras mais representativas em negrito.

Data de recebimento 21 de agosto de 2018, país de ocorrência Brasil parte interessada N.A. setor Agricultura. Alegante sindicato do setor das empresas financeiras e de seguros. Concluída, data de encerramento 04. 10. 2013.Tema Políticas Gerais, Divulgação, Direitos Humanos e Meio Ambiente. Alegante Fórum Suape, Conectas Direitos Humanos, Both Ends, Colônia de Pescadores do Município de Cabo de Santo Agostinho. País da ocorrência Brasil, alegante grupo setor manufatureiro. De acordo com os denunciantes a supracitada empresa multinacional incorreu em conduta qualificada como recall branco, temas: políticas gerais, divulgação, emprego e relações do trabalho, combate à corrupção, solicitação de suborno, extorsão e interesses do consumidor. 
Resumidamente, o segundo eixo trata das Diretrizes, sintetizando o perfil das denúncias levadas ao PCN Brasil e respondendo às perguntas sobre as alegaçóes de inobservância: quem denuncia, de onde denuncia, o que denuncia, porque denuncia e quando ocorreram as denúncias.

As análises lexicais corroboram as informaçóes constantes na base de dados da OCDE sobre o PCN Brasil. Nela, os temas mais denunciados de inobservância são, em número de reclamaçóes: políticas gerais (19); emprego e relaçôes empresariais (17); direitos humanos (12), divulgaçáo (9); meio ambiente (9); conceitos e princípios (5); combate ao suborno, solicitação de suborno e extorsão (1); defesa do consumidor (1). Em relação aos setores econômicos, os mais denunciados são: manufatureiro (10), financeiro (8) e de mineração (6). ${ }^{20}$

Em relação aos aceites de violaçóes recebidas, temos o seguinte quadro em relação ao status das denúncias: $56 \%$ foram concluídas; $25 \%$ não foram aceitas; e $19 \%$ estão em progresso. Lembramos que as concluídas não significam que as empresas que participam do processo de bons ofícios/mediação façam acordo, tampouco que modificam sua política depois de participar do processo. Entrevistas e relatórios anuais mostram que o processo de acompanhamento é muito recente no PCN Brasil, sendo também um conteúdo que não aparece na análise lexical, apesar de só termos tido acesso ao sumário das alegaçôes e não às declaraçôes finais e outros possíveis relatos de acompanhamento.

O perfil dos alegantes/partes interessadas mostra que os sindicatos são os que mais denunciam violaçóes, seguidos das ONGs. Os sindicatos, em sua maioria, são ligados à CUT e não a outras centrais sindicais, mostrando que esse tipo de organização é o que mais conhece e acessa esse instrumento, principalmente nos primeiros anos de sua implementação.

Em relação às ONGs, o corpus contém a informação sobre ONGs locais e uma ligada aos direitos humanos (Conectas Direitos Humanos), que apresenta várias alegaçóes. Não aparecem violaçôes advogadas por grandes e tradicionais ONGs brasileiras ligadas a questóes das Diretrizes, como Instituto Ethos de Responsabilidade Social, Instituto AKATU para o Consumo Consciente, IDEC, IBASE, ABONG e várias outras especializadas nos temas das Diretrizes. Esse quadro pouco diverso pode revelar um baixo grau de interlocuçáo com organizaçóes da sociedade civil, haja vista que o PCN Brasil é interministerial, mas não multipartite e não conta com um conselho consultivo, como recomenda a OCDE.

\subsection{Análise Fatorial de Correspondência (AFC)}

Em relação à AFC, podemos destacar a oposição das classes em diferentes partes do plano fatorial. Temos claramente as alegaçóes em curso (classe 1) versus alegaçóes não aceitas (classe 2). O eixo das classes 3, 4 e 5 é mais descritivo dos conteúdos mais expressivos das alegaçôes. Podemos observar, na figura 4, as seguintes oposições no Plano Fatorial, cuja forma lembra um coração. 
FIGURA 4

\section{Plano fatorial das alegações (2003-2020)}

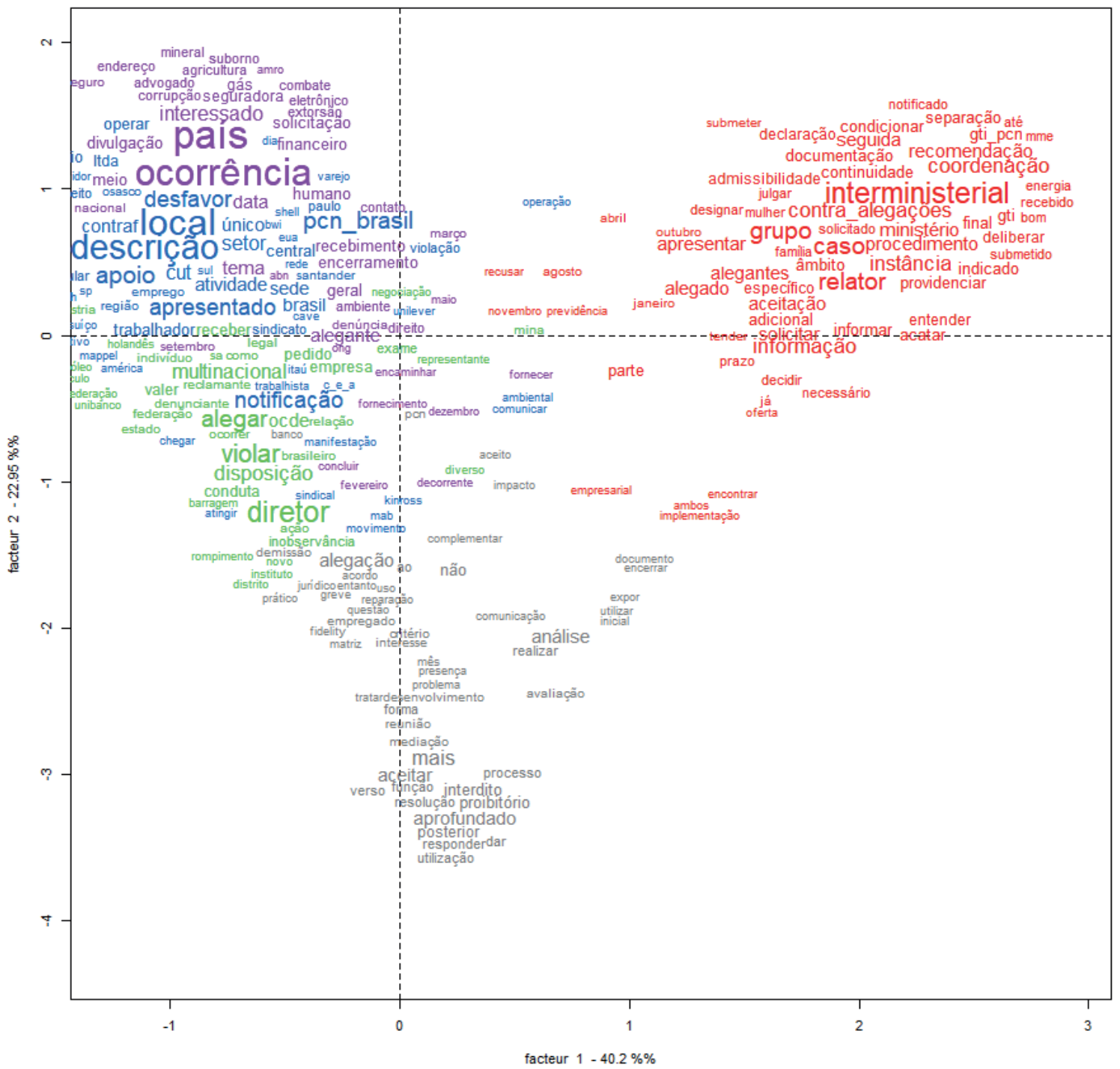

Elaboração da autora.

Obs.: Figura cujos leiaute e textos não puderam ser padronizados e revisados em virtude das condições técnicas dos originais (nota do Editorial).

\subsubsection{Primeira oposição: instâncias aceitas/em andamento versus não aceitas}

Quando observamos a classe 1(em vermelho), no plano direito superior, a maioria dos vocábulos mais representativos nitidamente se opóe aos da classe 2 (em cinza), no plano direito e esquerdo inferiores. Isso pode ser mais bem visualizado se olharmos as classes 1 e 2 na diagonal e nos atentarmos para as palavras mais significativas de cada classe. 


\subsubsection{Segunda oposição: em andamento versus concluídas ${ }^{21}$}

A classe 1 (em vermelho) está visivelmente em oposição ao agrupamento das classes 3 (verde), 4 (azul) e 5 (lilás), assim como à classe 2 (cinza), que concentra vocábulos típicos das alegaçôes não aceitas. Isso pode indicar a diferença de fases das submissóes das mais recentes para as mais antigas e já encerradas. Foram verificadas, no período da análise, nove instâncias abertas, sendo seis de 2020. No plano superior direito, o discurso contempla mais vocábulos da fase inicial do processo e do novo manual de procedimentos. Então teríamos na AFC as mais recentes (em andamento) em contraposição às já concluídas, que representam $81 \%$ das submissôes feitas ao PCN Brasil.

Um importante conteúdo da análise lexical é relativo a vocábulos e segmentos de texto relacionados ao processo de mediação, tais como bons ofícios, boa-fé, consenso, negociação, solução, remediação, reparação, entre outros. Como já foi dito, tivemos acesso apenas ao sumário, mas, sintomaticamente, as palavras mediação e acordo aparecem sem muito destaque, ${ }^{22}$ e no eixo do plano fatorial relativo às alegaçôes não aceitas. Isso é um forte indício de que poucas instâncias chegam a essa fase e estabelecem acordos. Desse modo, é necessário fortalecer a fase dos bons ofícios por meio de estratégias de comunicação e, principalmente, de persuasão. ${ }^{23}$

A leitura dos sumários revela que, das 38 alegaçóes, apenas quatro chegaram à fase da mediação e, desses casos, em apenas uma houve acordo - Kinross Canadense e Associação de Moradores de Paracatu, de 2013, em que a empresa se comprometeu a reparar casas dos três bairros objeto da alegação. Essa instância, inclusive, tornou-se um dos casos escolhidos no documento comemorativo dos 20 anos dos PCNs, intitulado National Contact Points for Responsible Business Conduct: Providing access to Remedy - 20 years and the road ahead (OECD, 2020).

Outro ponto que destacamos é que a recusa ou desistência das empresas e, por vezes, de alegantes e partes interessadas, sugere ainda a falta de conhecimento sobre o processo de mediaçáo, de sua natureza extrajudicial, dialógica, conciliatória e que pode trazer benefícios para as partes. Pode indicar ainda o medo que as empresas têm de prejudicar sua imagem e reputação, ao continuar as açóes, e também que não têm confiança no processo ou a preferência por processos judiciais. Para os outros agentes, como sindicatos e ONGs, pode também significar que optam por manter seus papéis e canais tradicionais (judiciais, legais e de confronto) a que já estão acostumados, em vez de buscar ou esperar por uma solução conciliatória nos termos do processo de mediação.

\section{CONSIDERAÇÕES FINAIS}

O objetivo desta pesquisa foi conhecer o conteúdo e as categorias temáticas (classes) das instâncias específicas recebidas pelo PCN Brasil no período de 2003 a 2020.

Os resultados apontam que esse discurso pode ser sintetizado em dois eixos. O primeiro, denominado Procedimentos do PCN Brasil, trata dos processos relativos ao andamento das denúncias,

21. Lembramos que concluídas podem ser as instâncias sem acordo (uma das partes não se engajou no processo), no qual a mediação foi alcançada, as não aceitas e as que resolveram a questão judicialmente. No PCN Brasil temos $25 \%$ de não aceitas, pequeno engajamento das empresas e alegantes que desistem do processo.

22. 0 tamanho da palavra relaciona-se com aos valores de frequência e $\chi^{2}$.

23. Note-se que a baixa participação na etapa de bons ofícios não acontece apenas no Brasil, mas em todos os PCNs. Desse modo, devem ser planejadas estratégias de comunicação e engajamento em conjunto com a OCDE, os PCNs e stakeholders. 
da análise cuidadosa para aceitação ou rejeição, do cumprimento das orientações da OCDE e do acompanhamento do GTI e das decisóes colegiadas da agência.

O segundo eixo, intitulado Diretrizes da OCDE para Empresas Multinacionais: quem denuncia e o que denuncia, nos permite conhecer o trâmite das instâncias. Pudemos conhecer os alegantes, os temas mais denunciados, as razóes das reclamaçóes e os locais onde ocorreram as violaçóes.

O plano fatorial apresenta as oposiçóes das classes (aceitas versus não aceitas; e concluídas versus em andamento) e os vocábulos característicos de cada classe. Os resultados indicam que o PCN Brasil tem seguido as recomendaçôes da OCDE na forma como lida com as instâncias. Além disso, apesar de recente, o manual de procedimentos tem colaborado para uma maior transparência e sistematização dos processos.

Os achados desta pesquisa indicam, no entanto, fraca interlocução com organizaçôes da sociedade civil e denúncias majoritariamente advindas de sindicatos. A fase dos bons ofícios precisa ser fortalecida, uma vez que um número reduzido de empresas aceitou participar da mediação, e isso se reflete na ausência lexical de vocábulos referentes aos acordos mútuos.

Entre as limitaçóes deste trabalho está o fato de termos analisado apenas o sumário dos processos e não os documentos relativos às declaraçôes finais. Quando o sistema de tecnologia de informação responsável pelo lançamento desses documentos na base de dados vier a disponibilizá-los, análises mais completas poderáo ser feitas. Com um corpus formado por documentos mais completos, sugere-se também examinar o impacto do manual de procedimentos nos processos relativos às reclamaçóes a partir de 2020. Outrossim, realizar estudos de caso com as multinacionais que aceitaram participar dos processos de mediação e com as partes (alegantes e alegados) que se recusaram a fazê-lo.

\section{REFERÊNCIAS}

BACKER, L. C. Rights and accountability in development (RAID) $v$ das air and global witness $v$ afrimex: small steps towards an autonomous transnational legal system for the regulation of multinational corporations. Melbourne Journal of International Law, May, 2009, v.10, n. 1, p. 258(50).

BARDIN, L. Análise de conteúdo. Lisboa: Edições 70, 2007.

BRASIL. Ministério da Economia. Ponto de contato nacional do Brasil. Manual de procedimentos para instâncias específicas. Brasília: ME, 2020. Disponível em: <https:/www.gov.br/produtividade-e-comercioexterior/pt-br/assuntos/camex/pcn/produtos/formularios/pcn-manual-de-procedimentos-para-instancias.pdf $>$. Acesso em: 5 jan. 2021.

LIMA, L. A articulação "themata-fundos tópicos": por uma análise pragmática da Linguagem. Psicologia: Teoria e Pesquisa. v. 24. n. 2. 2008. p. 243-246.

OECD - ORGANISATION FOR ECONOMIC COOPERATION AND DEVELOPMENT. The OECD guidelines for multinational enterprises. Japanese NCP: peer learning and review. Paris: OECD, 2012. Disponível em: <https://www.oecd.org/daf/inv/mne/JapaneseNCPReview.pdf>.

Annual report on the OECD guidelines for multinational enterprises 2018. Paris: OECD, 2019. Disponível em: <http://mneguidelines.oecd.org/2018-Annual-Report-MNE-Guidelines-EN.pdf>.

National contact points for responsible business conduct providing access to remedy - 20 years and the road ahead. Paris: OECD, 2020. Disponível em: <http://mneguidelines.oecd.org/NCPs-for-RBCproviding-access-to-remedy-20-years-and-the-road-ahead.pdf>. 
OECD responsible business conduct. Paris: OECD, 2021. Disponível em: $<$ http://mneguidelines. oecd.org/ncps/NCPs-at-20/>. Acesso em: 24 fev. 2021.

OECD WATCH. NCP evaluations. Amsterdam: OECD Watch, 2021. Disponível em: <https://www. oecdwatch.org/indicator/>. Acesso em 27 fev. 2021.

OLIVEIRA, D. C.; GOMES, A. M. T.; MARQUES, S. C. Análise estatística de dados textuais na pesquisa das representaçóes sociais: alguns princípios e uma aplicação ao campo da saúde. In: MENIN, M. S. S; SHIMIZU, A. M. (Orgs.). Experiência e representação social: questôes teóricas e metodológicas. São Paulo: Casa do Psicólogo, 2005. p. 157-200.

SALVIATI, M. E. Manual do Aplicativo Iramuteq (versão 0.7 Alpha 2 e R Versão 3.2.3). Planaltina: [s.n.], 2017. Disponível em: <http://www.iramuteq.org/documentation/fichiers/manual-do-aplicativo-iramuteqpar-maria-elisabeth-salviati>. 
